\section{Chronische Niereninsuffizienz: Proteinurie wichtiger als GFR?}

\section{Beeinflusst der Schweregrad der Proteinurie innerhalb einer vorgegebenen Einschränkung der glomerulären Filtrationsrate das allgemeine Mortalitätsrisiko von niereninsuffizienten Patienten? Kanadische Wissenschaftler versuchten diese Frage anhand der Daten einer großen Populationskohorte zu beantworten.}

$\mathrm{D}$ gegenwärtige Einteilung der Niereninsuffizienz in fünf Stadien basiert im Wesentlichen auf der geschätzten glomerulären Filtrationsrate (GFR), die annäherungsweise anhand des Serumkreatinins, des Alters und des Geschlechts errechnet wird. Kritiker dieser Klassifikation bemängeln, dass das Ausmaß der Proteinurie bei diesem Einteilungsschema vernachlässigt wird, obwohl bekannt ist, dass eine Einschränkung der GFR nicht immer mit einer Proteinurie einhergeht.

Anhand der zwischen 2002 und 2007 erhobenen Daten einer großen Populationskohorte in der kanadischen Provinz Alberta mit fast einer Million Teilneh- mern wurde nun der Einfluss der Proteinurie auf die klinische Gesamtprognose untersucht. $89 \%$ der Personen hatten eine geschätzte GFR von $60 \mathrm{ml} / \mathrm{min} /$ $1,73 \mathrm{~m}^{2}$ oder mehr.

Im Verlauf eines im Median 35 Monate dauernden Follow-ups verstarben 27.959 Teilnehmer (3,0\%). Die adjustierte Mortalitätsrate von Teilnehmern mit einer GFR von über $60 \mathrm{ml} / \mathrm{min}$ und einer schweren Proteinurie war um das Doppelte höher als die Rate von Personen mit einer GFR zwischen 45 und $59,9 \mathrm{ml} / \mathrm{min}$ und normaler Proteinexkretion (7,2 vs. 2,9 pro Tausend Personenjahre).

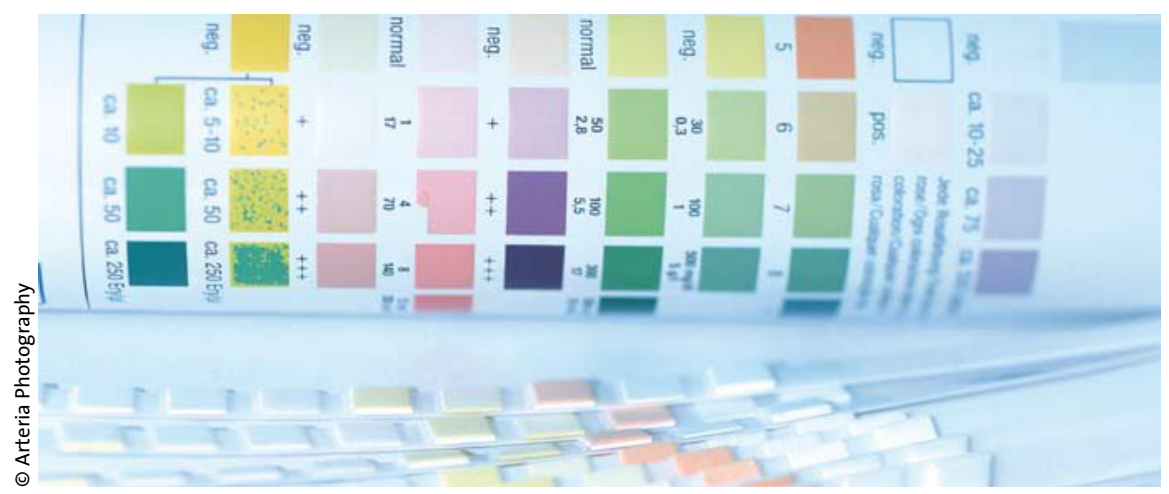

Welche Werte charakterisieren eine Niereninsuffizienz am besten?

Ähnliche Resultate ergaben sich, wenn der Albumin-Kreatinin-Quotient herangezogen wurde. Aufgrund der Bedeutung der Proteinurie für die Gesamtprognose plädieren die Autoren dafür, bei der Graduierung der Niereninsuffizienz neben der GFR auch das Ausmaß der Proteinurie mit heranzuziehen. Zum Beispiel hätte ein Patient mit einer GFR von $80 \mathrm{ml} / \mathrm{min}$ und einer dreifach positiven Proteinurie im Streifentest nach der bisherigen Klassifikation nur eine Niereninsuffizienz Grad 1, obwohl sein altersadjustiertes Mortalitätsrisiko und die Notwendigkeit einer Nierenersatztherapie zwei- bis zehnfach höher ist als bei einem ähnlichen Patienten mit einer GFR von nur $50 \mathrm{ml} / \mathrm{min}$, jedoch ohne Proteinurie. Die Niereninsuffizienz des letztgenannten Patienten würde allerdings als Stadium 3 eingestuft werden.

\section{Kommentar}

Obwohl es sich bei der Untersuchung nur um eine Beobachtungsstudie handelt, die zudem wichtige zusätzliche prognostische Parameter wie antihypertensive Therapie, Rauchen und Alkoholkonsum nicht berücksichtigt, sind die Daten allein aufgrund der großen Zahl doch sehr überzeugend. Nachdem bei den meisten Patienten mit Niereninsuffizienz ohnehin irgendwann einmal ein Urinstreifentest durchgeführt wurde, wäre es bereits jetzt problemlos möglich, den Parameter der Proteinurie bei der Prognosebeurteilung zu berücksichtigen.

Prof. Dr. med. Hermann S. FüeßI

Hemmelgarn BR et al. Relation between kidney function, protein-uria and adverse outcomes. JAMA 2010; 303: 423-9 